\title{
Evaluation of an improvement strategy on the incidence of medication prescribing errors in a pediatric intensive care unit
}

\author{
Pedro Taffarel, M.D., ${ }^{a}$ Claudia Meregalli, M.D. , ${ }^{a}$ Facundo Jorro Barón, M.D., ${ }^{a}$ \\ Carolina Sabatini, B.S., Mariana Narbait, M.D., ${ }^{b}$ and Gustavo Debaisi, M.D. ${ }^{a}$
}

\begin{abstract}
Medical prescribing errors (MPEs) are one of the most common causes of adverse events. Intensive care units are a high-risk setting for their occurrence.

Objectives. To describe the incidence and types of MPEs in our Pediatric Intensive Care Unit.

To assess whether the implementation of an improvement strategy on MPEs affects their incidence in the short- and long-term.

Population and Methods. Prospective, uncontrolled, before-after study.

Universe and sample. All medical prescriptions for patients hospitalized in the Pediatric Intensive Care Unit of the Hospital General de Niños Pedro de Elizalde from July-December, 2013 and from July-August, 2014.

Results. In the pre-intervention period, MPEs rate was $13.9 \%$, the most common being the absence of the time a given medication was modified, followed by missing a dose or medication. The medication most frequently involved in MPEs was the sedation and continuous analgesia group. After the implementation of an improvement program on MPEs, the incidence decreased to 6.3 errors every 100 prescriptions.

The MPE type which showed the greatest reduction was the absence of the time of modification. Except for parenteral hydration and electrolyte supplementation, the rest of the analyzed medication groups showed a marked reduction. One year after having reviewed the situation, the MPE rate was 5.8\%, and values remained similar to those of the immediate postintervention period.

Conclusion. Managing an improvement program on MPEs resulted in a decrease in its incidence. Key words: patient safety, adverse events, medical errors, inadequate prescription.
\end{abstract}

http:/ /dx.doi.org/10.5546/aap.2015.eng.229

Clinical trial registration: Registered and approved at the Research Project Registry of the City of Buenos Aires under number 161/13.

\section{Funding:}

None.

Conflict of interest:

None.

Received: 11-07-2014 Accepted: 1-30-2015 in medication misuse. ${ }^{1}$

The process of medication use includes five important stages: prescribing, dispensing, transcribing, preparing and administering; the two most vulnerable stages are the processes of prescribing and administering. ${ }^{2}$

The wide range of MPE causes include, but are not limited to: lack of knowledge about medication management, verbal prescriptions or illegible or incomplete written prescriptions, undertrained staff, lack of standardized protocol preparation and management, lack of a pharmacist in the unit, lack of error detection and prevention programs, among others. ${ }^{3}$

Patients in the Intensive Care Unit (ICU) experience 1.7 clinical errors daily, and many of them are exposed to a potentially fatal error during their stay. ${ }^{4}$ MPEs account for $78 \%$ of serious errors in the ICU. ${ }^{5}$

For those patients hospitalized in the ICU, medication must be determined based on weight, body surface area, maximum and minimum doses, and titration according to renal and/or liver function, which increases the likelihood of prescribing errors. ${ }^{6}$

There are differences in the MPE incidence reported in the literature due to the different quantification and classification methods used. In Pediatric Intensive Care Units (PICU), MPE rates range from $11 \%$ to $39 \% .7,8$

It is essential to develop within the ICUs a culture which promotes and encourages the implementation of preventive measures tending to reduce MPE rates, as well as the need to elucidate and communicate the error identified, as an opportunity to learn and improve patients' safety. 


\section{OBJECTIVES}

\section{Specific objectives}

To report the incidence and types of medical prescribing errors in the ICU of Hospital General de Niños Pedro de Elizalde (HGNPE).

To assess whether the implementation of an improvement strategy on MPEs affects their incidence in the short- and long-term.

\section{MATERIAL AND METHODS}

\section{Study design}

Prospective, uncontrolled, before-after study. Approved by the HGNPE Ethics Committee and Teaching and Research Department.

\section{Description of the study setting}

This study was carried out at the PICU at HGNPE, which has 11 beds for patients between one month and 18 years old with different conditions except for postoperative cardiovascular surgery and transplanted patients.

In our Unit, prescriptions are handwritten and re-written every 24 hours during morning rounds, unless changes take place during the on duty or on call services.

\section{Universe and sample}

All medical prescriptions for patients at the HGNPE PICU, issued from July-December, 2013 and from July-August, 2014.

\section{Exclusion criteria}

All prescriptions of cytotoxic agents and feeding formulas (enteral or parenteral), since they are not prepared in the PICU.

\section{Sample size calculation}

It was estimated based on an MPE incidence of $15 \%$ (data recorded during 2012) for all prescriptions issued at our hospital's PICU. In order to detect a 30\% error reduction, and assuming an $80 \%$ statistical power and a $5 \%$ Alpha error, the minimum sample required for each period was 1500 prescriptions.

\section{METHODOLOGY}

The study was carried out in four periods. During the "pre-intervention period" (July and August, 2013), both the MPE incidence and type, as well as their severity according to the RuizJarabo group classification were determined ${ }^{8}$ (Tables 1 and 2). The next was the "intervention period", from September to October, 2013, when the improvement program on MPEs was introduced. Then there was a third period, the "immediate post-intervention period" (November and December, 2013), where the whole package of measures aiming at reducing MPEs was implemented, and the incidence was measured. Finally, the fourth and last period, the "longterm post-intervention period" (July and August, 2014), in which MPE incidence was determined, without any intervention, except for continuing with computerized instructions.

The main outcome measure was the incidence of MPEs during the different phases of the study; MPE rate was stated as the number of MPEs per 100 prescriptions. Outcome measures related to clinical and demographic data of inpatients during the study period were also analyzed.

Data collection for MPE quantification was

TABLE 1. Type of errors in medical prescriptions

\begin{tabular}{ll} 
Type of error & Description \\
\hline Erroneous medication & $\begin{array}{l}\text { Inadequate selection of the medication: medication not advisable or nor appropriate } \\
\text { for the diagnosis to be treated. } \\
\text { Previous history of allergy or adverse events related to the same } \\
\text { or similar medications. } \\
\text { Contraindicated medication. } \\
\text { Treatment duplication. Unnecessary medication. }\end{array}$ \\
\hline Missing dose or medication. & Not filling a prescription of the necessary medication or corresponding dose. \\
\hline Wrong dose. & $\begin{array}{l}\text { Dose higher than the correct one. Dose lower than the correct one. } \\
\text { Error in the medication unit. }\end{array}$ \\
\hline Wrong dosing interval & $\begin{array}{l}\text { Prescription of a medication in a time dosing interval other than that needed } \\
\text { by the patient. }\end{array}$ \\
\hline Modification time is missing & \\
\hline Illegibility & Administration of a medication through a route different from the approved one. \\
\hline Wrong route of administration & \\
\hline Route of administration not specified & \\
\hline
\end{tabular}


performed through the review of medical records and medical prescription sheets, which was carried out by professionals in charge of the task, and took place 24 hours after having issued the prescription. Reviewers were not in charge of the prescription process.

\section{DATA COLLECTION INSTRUMENT (See Annex 1)}

Proposed intervention (See Annex 2)

A multifactorial approach measure package was implemented. Low technology cost-effective measures were applied (training of staff on patient safety; daily feedback on MPEs; updated edition of drug and treatment formularies; laminated charts of dilution and infusion guidelines for main drugs), and a measure of higher cost and technology: a computerized prescription system. Besides, a pharmacist was included in the PICU team.

\section{Statistical analysis}

MPE incidence was analyzed for each period. Categorical outcome measures were expressed as absolute values or percentages, and continuous outcome measures, as central position measures plus their respective dispersion measures. Upon verification of data normality through ShapiroWilk test, MPE incidence between periods was compared using the Student's t-test. A p-value $\leq 0.05$ was considered statistically significant. A one-way ANOVA test was used to assess the significance of variation within the total number of prescriptions in the periods under study. Data were analyzed with the STATA 10.1 software.

\section{Permission}

No informed consent was required to carry out this study.

The project was approved by the HGNPE Ethics Committee and Teaching and Research Department.

Research Registry of the City of Buenos Aires under number 161/13.

\section{RESULTS}

During the first 6 months of the study (from July to December, 2013), 186 patients were hospitalized at the HGNPE ICU. A total of 1270 medical indication sheets and 16 334 prescriptions were analyzed. The average of prescriptions/day and prescriptions/patient were 89.2 and 12.9 , respectively.

\section{DIAGNOSIS OF THE SITUATION, PRE-INTERVENTION PERIOD}

As regards MPE classification during this period, the most frequent error was the lack of modification time of a given medication, with $53.2 \%$ of all MPEs, followed by missing a dose or drug, and illegibility, with $18.3 \%$ and $8 \%$, respectively; while the prescription of a wrong

TABLE 2. Severity of medical prescription errors according to Ruiz-Jarabo's taxonomy

\begin{tabular}{|c|c|c|}
\hline Type of error & Category & Definition \\
\hline No error & Categoy A & Circumstances or events which are potential causes of error. \\
\hline \multirow[t]{3}{*}{ Error, but no harm ${ }^{\mathrm{a}}$} & Category $B$ & An error occurred which did not involve the patient. ${ }^{b}$ \\
\hline & Category C & An error occurred which involved the patient but did not cause any harm. \\
\hline & Category D & $\begin{array}{l}\text { An error occurred which reached the patient and required monitoring in order } \\
\text { to confirm the patient had suffered no harm and/or required an intervention to } \\
\text { prevent it from occurring. }\end{array}$ \\
\hline \multirow[t]{4}{*}{ Error and harm } & Category E & $\begin{array}{l}\text { An error occurred which could have contributed to or caused temporary harm } \\
\text { to the patient, and required intervention. }{ }^{\mathrm{d}}\end{array}$ \\
\hline & Category F & $\begin{array}{l}\text { An error occurred which could have contributed to or caused temporary harm } \\
\text { to the patient, and required initial or long-term hospitalization. }\end{array}$ \\
\hline & Category G & $\begin{array}{l}\text { An error occurred which could have contributed to or caused permanent harm } \\
\text { to the patient. }\end{array}$ \\
\hline & Category $H$ & An error occurred which required a necessary intervention to sustain life. ${ }^{e}$ \\
\hline Error, death & Category I & An error occurred which could have contributed to or caused the patient's death. \\
\hline
\end{tabular}

\footnotetext{
${ }^{a}$ Harm: damage to the physical, emotional or psychological function or structure of the body and/or resulting pain.

b An "error of omission" which involves the patient.

${ }^{\mathrm{c}}$ Monitoring to observe or record relevant physiological or psychological signs.

${ }^{\mathrm{d}}$ Intervention: it may include a a change in therapy or in the active medical/surgical treatment.

e Necessary intervention for life support: it includes cardiovascular and respiratory support [e.g., cardiopulmonary resuscitation (CPR), defibrillation, intubation, etc.].
} 
medication and of a wrong dose accounted for $6.8 \%$ of all MPEs.

As regards error severity, depending on whether or not the patient was harmed, and categorized by Ruiz-Jarabo ${ }^{8}$ classification, $89 \%$ were category B errors, $9.7 \%$, category $C$, and the rest of the categories accounted for the remaining $1.3 \%$. It should be noted that there were no errors during this study which might have contributed to or caused a patient's death.

An analysis of the drugs involved in the MPEs during this period revealed that the continuous sedation-analgesia group accounted for the higher percentage, with $17.2 \%$, followed by the intermittent sedation-analgesia group and antimicrobials, with $14 \%$ and $13.8 \%$, respectively. Of the total MPEs, $24.8 \%$ were included under the category named "Others".

\section{IMMEDIATE POST-INTERVENTION PERIOD, ASSESSMENT OF THE IMPROVEMENT STRATEGY}

In order to make an objective assessment of the measures implemented to reduce the incidence of MPEs, the first three periods of the study, namely: the pre-intervention period (JulyAugust), the intervention period (SeptemberOctober) and the post-intervention period (November-December) were analyzed. The main clinical and demographic characteristics and the number of prescriptions for the different periods are shown in Table 3.

Though the number of prescriptions varied between the different periods analyzed (with the highest number during the pre-intervention period), these differences were not significant within the total number of prescriptions in the time frames considered $(\mathrm{F}=0.089 ; \mathrm{p}=915)$.

The total number of MPEs in the pre- and post-intervention periods was analyzed and a $54.7 \%$ MPE reduction was observed $(\mathrm{p}<0.001)$ (Figure 1).

Finally, pre-intervention, intervention and post-intervention periods were analyzed and compared as far as type (Figure 2), severity and medications involved in MPEs (Figure 3). So as to endorse and compare results obtained from the three periods, they were expressed as rate per 100 prescriptions.

The main reduction in MPEs associated to error type was observed for the lack of modification time for a given medical indication (73\%).

As to MPE severity, there was a $56 \%$ and a $48 \%$ decrease in categories B and C (error does not harm the patient), respectively, during the post-intervention period, while no differences were observed in the rest of the categories (which imply a greater severity).

Lastly, when comparing pre- and postintervention periods in relation to the medication involved in the error, except for the item Parenteral fluid and electrolyte therapy which remained unchanged, the rest of the analyzed medication groups showed a marked reduction in the last period, which was $75 \%$ for vasoactive drugs and inotropes, $63 \%$ for intermittent sedation-analgesia and neuromuscular blocking

TABLE 3. Clinical and demographic characteristics, and number of prescriptions for the first three period

\begin{tabular}{|c|c|c|c|}
\hline & $\begin{array}{l}\text { Pre-intervention } \\
\text { July-August }\end{array}$ & $\begin{array}{c}\text { Intervention } \\
\text { September-October }\end{array}$ & $\begin{array}{c}\text { Post-intervention } \\
\text { November-December }\end{array}$ \\
\hline Total number of prescriptions & 6320 & 4864 & 5150 \\
\hline Prescription sheets per patient & 492 & 373 & 405 \\
\hline Average number of prescriptions per day & 102 & 78 & 84.4 \\
\hline Average number of prescriptions per patient & 12.8 & 13 & 12.7 \\
\hline Total number of patients & 86 & 64 & 49 \\
\hline MPE rate per 100 prescriptions & 13.9 & 13.2 & 6.3 \\
\hline Age in months, median (IQ range) & $9(5-33)$ & $16(4-65)$ & $30(6-108)$ \\
\hline PIM2, median (IQ range) & $5(1.1-10.9)$ & $3(1.3-8.8)$ & $4.9(0.6-12.1)$ \\
\hline $\begin{array}{l}\text { Length of stay, in days; median } \\
\text { (standard deviation) }\end{array}$ & $6.6(8.3)$ & $6.8(9.3)$ & $9.3(11.2)$ \\
\hline Average occupancy (\%) & $82.8 \%$ & $67.1 \%$ & $68 \%$ \\
\hline Mortality (N) (\%) & $6(7 \%)$ & $4(6.2 \%)$ & $3(6.1 \%)$ \\
\hline
\end{tabular}

MPE: medical prescription error. PIM2: Pediatric Index of Mortality 2. 
agents, $58 \%$ for continuous sedation-analgesia, and $53 \%$ for antimicrobials, while drugs under the category "Others" showed a $65 \%$ reduction in MPEs.

\section{POSTINTERVENTION PERIOD LONG-TERM}

The incidence of MPEs was determined in
July and August, 2014, one year after having diagnosed the situation and 8 months after having implemented the improvement package. No other intervention has taken place ever since, except for continuing with the computerized prescription system. A 5.8\% MPE rate has been observed.

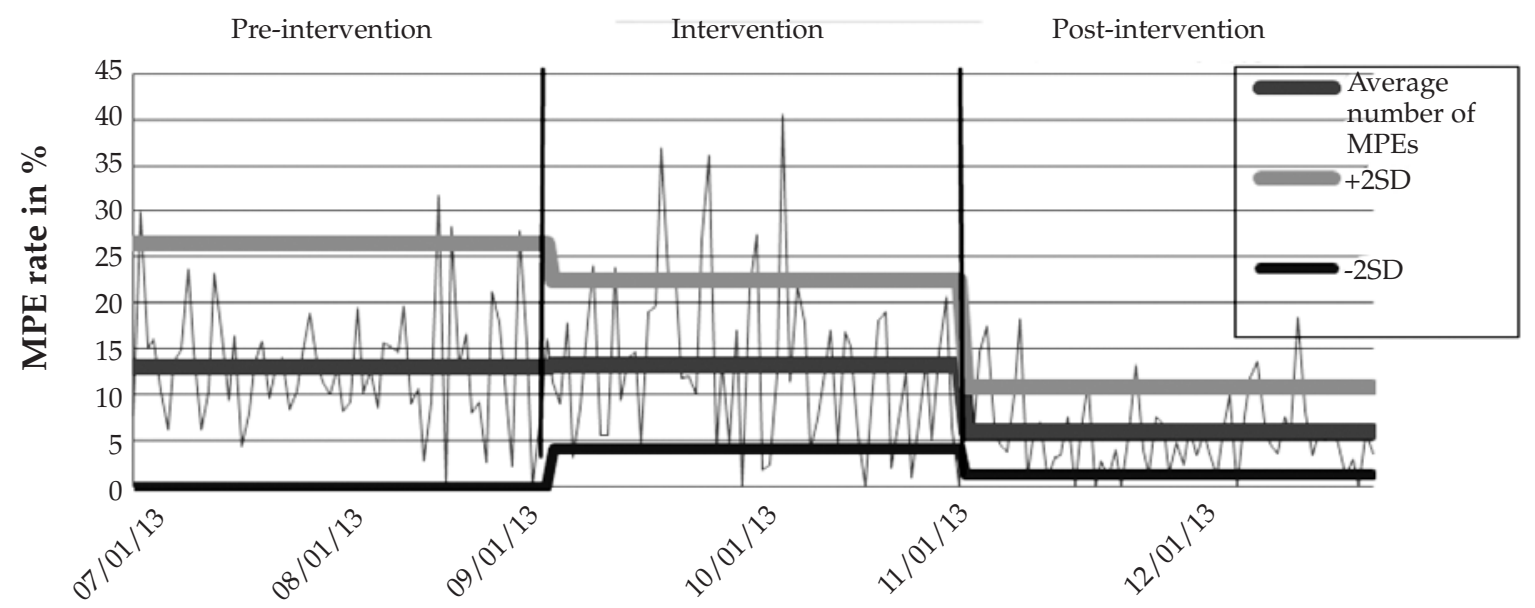

MPE: medical prescription error; SD: standard deviation.

FIGURE 2. Comparison of medical prescription errors (MPEs) during the first three periods

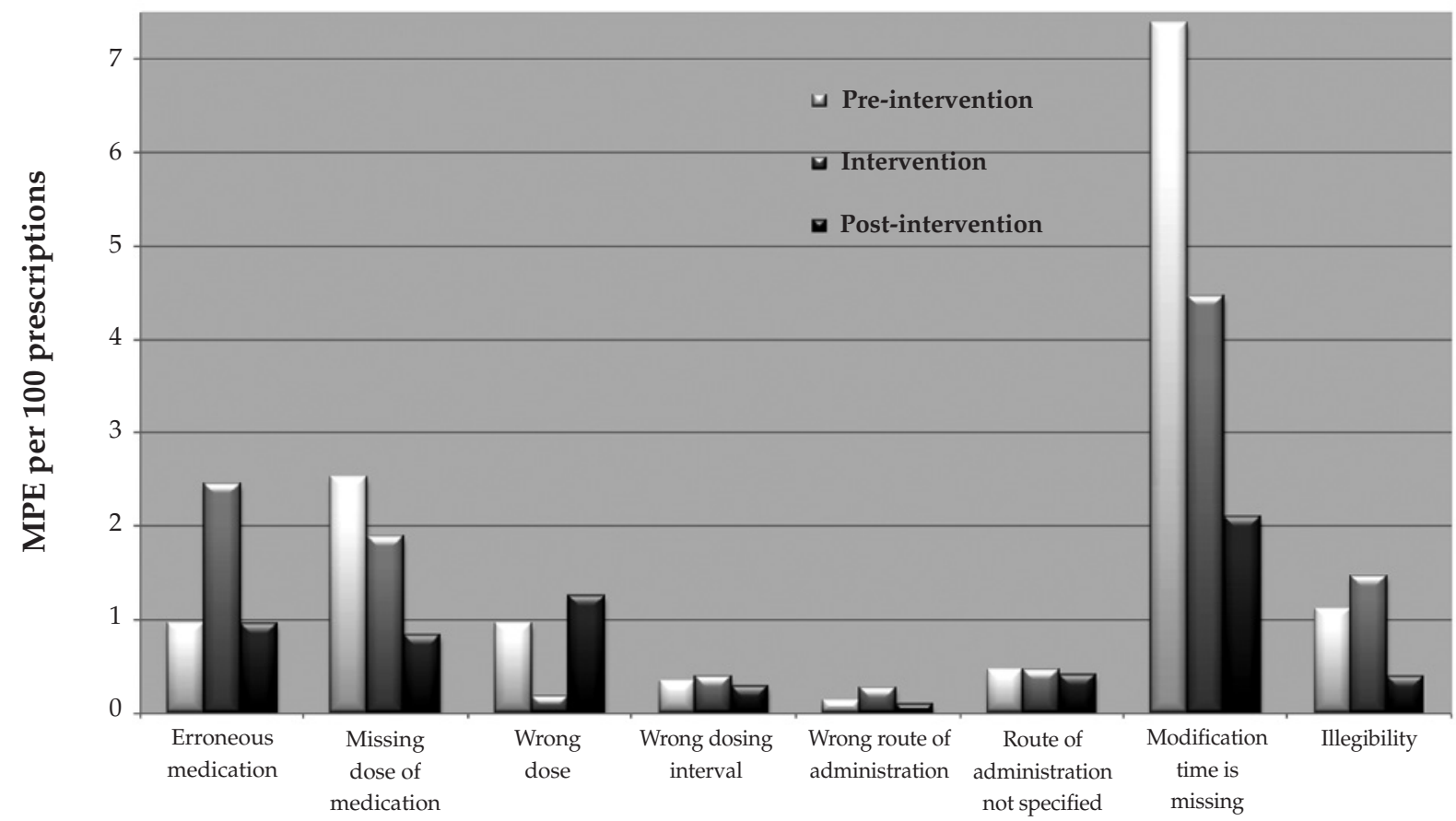

Type of errors 


\section{DISCUSSION}

Medical literature includes different publications aiming at the reduction of medication errors, but many of them differ in the definition of a MPE. The main hurdle is whether considering or not errors that do not cause harm, ${ }^{9}$ thus, the incidence reported shows a marked variation. Our work includes MPEs whether or not they have caused harm, and assumes that harm frequency is proportional to that of incidents without harm.

Error counts have been performed based on the review of prescription sheets and medical records. Since an observation is reported as an error, literature introduces a bias when using this system. ${ }^{10}$ In order to minimize this, MPE count in this work was subject to the consensus of physicians and pharmacist in charge.

As regards the results of this work, MPE incidence during the pre-intervention period was of 13.9 errors per 100 prescriptions. This incidence falls on the lower limit described in the literature, which ranges from $11 \%$ to $39 \%$, and can reach up to $78 \%$, as shown by Alagha et al. ${ }^{11}$

Incidence by type of error differs in the literature depending on the classification used. Thus, Otero et al. ${ }^{12}$ submitted similar values for the absence of modification time and for the omission of a given drug during the preintervention period, of $42 \%$ and $13 \%$, respectively. In Martínez et al.' ${ }^{8}$ research, the most common error during the diagnosis period was non specified route of administration, with a $28.6 \%$. Finally, Booth et al. ${ }^{13}$ showed a higher incidence for errors in dose and dosing intervals.

As regards MPEs severity during the initial period, the pooled categories which did reach the patient accounted for $11 \%$ of MPEs, figure which exceeded the values published by another PICU $^{8}$ $(0.6 \%)$.

As for the drug involved in the error during the first period analyzed, the continuous sedationanalgesia group showed the greatest error percentage, with $17.2 \%$, followed by intermittent sedation-analgesia and antimicrobials, feature shared by Martínez-Anton et al.'s research, with a similar percentage. ${ }^{8}$

The medical literature consulted regarding the implementation of improvement strategies on other PICU's MPEs, ${ }^{8,12,13}$ shows they differ not only in the measures taken but also in how long the intervention lasted. Most reported measures, except for the creation of a specific place devoted to the origin of indications, ${ }^{13}$ were also part of

FIGURE 3. Comparison of drugs involved in medical prescription errors (MPEs) during the first three periods

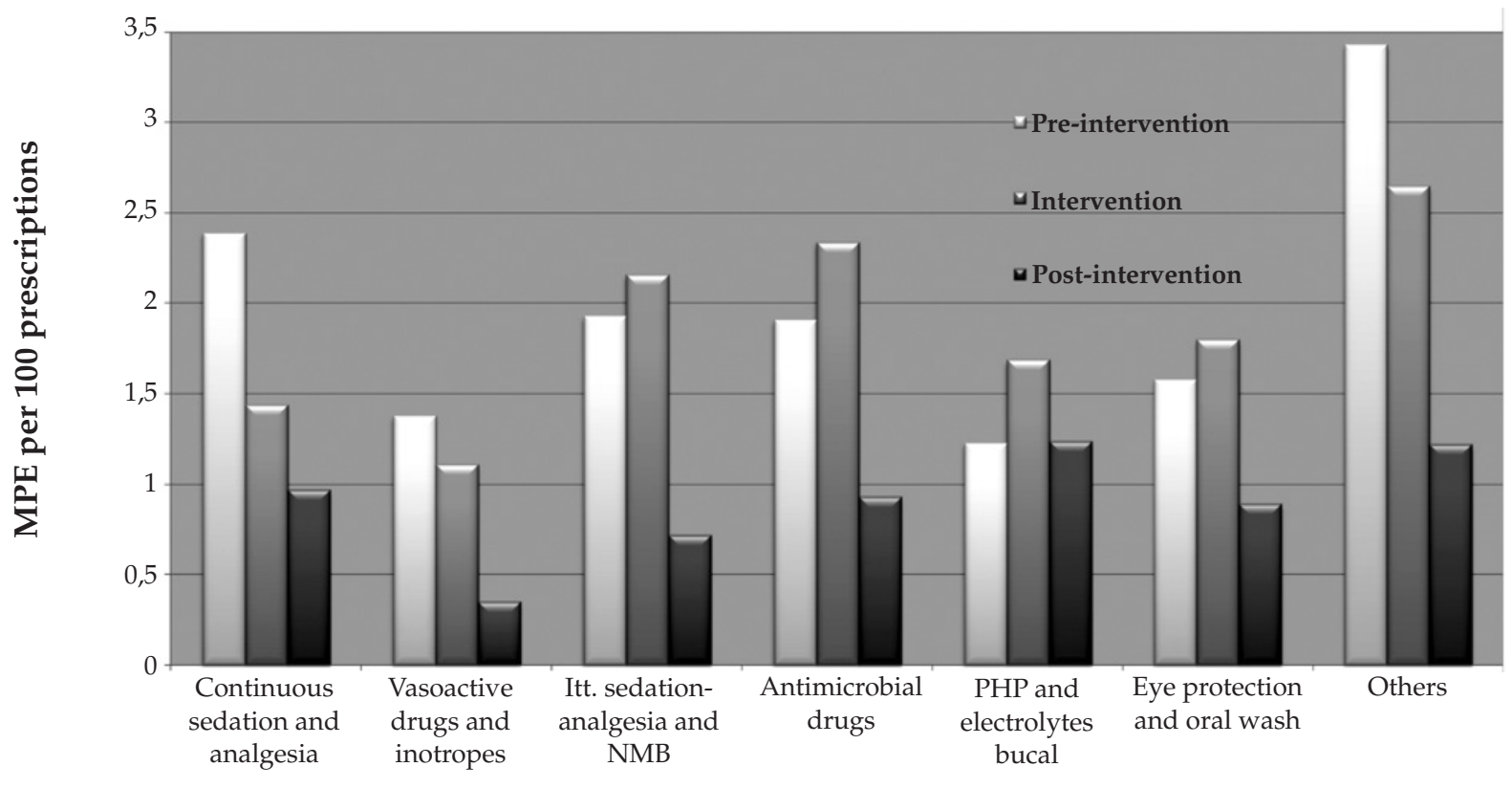

Type of medication

Itt.: intermittent.

NMB: neuromuscular blocking.

PHP: parenteral hydration plan. 
our project which additionally included the creation and implementation of a computerized prescription system. The review of the effect of the computerized system on MPEs at 4 adult ICUs, 4 PICUs and/or Neonatal Intensive Care Units (NICUs), and 4 pediatric units ${ }^{14}$ showed a significant reduction in MPEs.

The computerized system implementation evidenced some difficulties featured as resistance to change, but only for a short time, since the team in charge of the task supervised and trained the rest of the medical team during the intervention period.

As compared to the first period and upon the implementation of a package of measures, an MPE reduction of $54.7 \%$ was observed during the third research period.

Other projects with similar design showed reductions of nearly $35 \%,{ }^{8,12}$ while Booth et al., ${ }^{13}$ who estimated the incidence of errors based on a rate every 1000 occupied bed days at the PICU, achieved a post-intervention absolute risk reduction of $44.5 \%$.

As regards the drug involved in the error, except for the PHP and electrolytes group, the rest showed a significant reduction in the error rate.

With respect to MPE type, wrong dose error was the only one to undergo a post-intervention rise $(33 \%)$. The results of Martínez-Anton's project $^{8}$ showed a significant reduction only for omission and illegibility errors, while the principal reductions published by Otero ${ }^{12}$ were seen for the dose interval, followed by absence of modification time, with omission and illegibility increasing during the post-intervention period.

A possible limitation of the study is the fact that the error documentation method is based on the revision of prescription sheets and medical records, which may induce the Haw thorne effect, i.e. subjects improve or modify their behavior because they are being observed and not as a response to an intervention..$^{15}$ In order to minimize or neutralize this effect, the group in charge of this task quantified the MPE rate and the impact of the strategy implemented in the long term (July and August, 2014) when health care providers felt they were not being observed. MPE rate was $5.8 \%$, a similar value to that of the immediate post-intervention period.

The Department where the research was carried out has developed other lines of research aimed at improving patients' safety. ${ }^{16}$ This has led to an important change in attitude towards errors. We believe that, regardless of the final result pursued by each project, this cultural change is the most important achievement among the implemented programs.

\section{CONCLUSION}

Managing an improvement program on MPEs resulted in a decrease in the incidence.

The improvement shown by indicators after the implementation of the medical prescription process optimization program proves the hypothesis of the research and, in addition, evidences the need and the importance of carrying out a health risk management program to be applied not only to the event under study, but also to all processes carried out at any health institution.

\section{REFERENCES}

1. National Coordinating Council for Medication Error Reporting and Prevention. About Medication Error: What is a medication error? [Accessed on: December 5, 2012]. Definition. Available at: http:/ / www.nccmerp.org/ aboutmedication-errors.

2. Moyen E, Camiré E, Stelfox H. Clinical review: Medication errors in critical care. Crit Care 2008;12(2):208.

3. Tissot E, Cornette C, Demoly P, Jacquet M, et al. Medication errors at the administration stage in an intensive care unit. Intensive Care Med 1999;25(4):353-9.

4. Camiré E, Moyen E, Stelfox H. Medication errors in critical care: risk factors, prevention and disclosure. $\mathrm{CMAJ}$ 2009;180(9):936-43.

5. Rothschild J, Landrigan C, Cronin J, Kaushal R, et al. The critical care safety study: The incidence and nature of adverse events and serious errors in intensive care. Crit Care Med 2005;33(8):1694-700.

6. Cheston M, Berlin C, Mc Carver D. Committee on Drugs and Committee on Hospital Care. American Academy of Pediatrics. Prevention of medication errors in the pediatric inpatient setting. Pediatrics 1998;102(2 Pt 1):428-30.

7. Cimino M, Kirschbaum M, Brodsky L, Shaha S, et al. Assessing medication prescribing errors in pediatric intensive care units. Pediatr Crit Care Med 2004;5(2):124-32.

8. Martinez-Anton A, Sanchez J, Casanueva L. Impact of an intervention to reduce prescribing errors in a pediatric intensive care unit. Intensive Care Med 2012;38(9):1532-8.

9. Resar R, Rozich J, Classen D. Methodology and rationale for the measurement of harm with trigger tools. Qual Saf Health Care 2003;12(Suppl. 2):ii39-45.

10. Dean B, Schachter M, Vincent C, Barber N. Prescribing errors in hospital inpatients: their incidence and clinical significance. Qual Saf Health Care 2002;11(4):340-4.

11. Alagha H, Badary OA, Ibrahim H, Sabri N. Reducing prescribing errors in the paediatric intensive care unit: an experience from Egypt. Acta Paediatr 2011;100(10):e169-74.

12. OteroP,LeytonA,MarianiG,CerianiCernadas J.Medication Errors in Pediatric Inpatients: Prevalence and Results of a Prevention Program. Pediatrics 2008;122(3):e737-43.

13. Booth R, Sturgess E, Taberner-Stokes A, Peters M. Zero tolerance prescribing: a strategy to reduce prescribing errors on the paediatric intensive care unit. Intensive Care Med 2012;38(11):1858-67.

14. Van Rosse F, Maat B, Rademaker CM, van Vught AJ, et al. The Effect of Computerized Physician Order Entry 
on Medication Prescription Errors and Clinical Outcome in Pediatric and Intensive Care: A Systematic Review. Pediatrics 2009;123(4);1184-90.

15. McCarney R, Warner J, Iliffe S, van Haselen R, et al. The Hawthorneeffect: arandomised, controlledtrial. BMCMed Res Methodol 2007;7:30.
16. MeregalliC, JorroBarónF, D'AlessandroM, Danzi E, Debasi G. Impacto de una intervención de mejora de calidad sobre la incidencia de extubaciones no planeadas en una unidad de cuidados intensivos pediátricos. Arch Argent Pediatr 2013;111(5):391-7. 


\section{Annex 1.}

\section{Data Collection Sheet}

MPE DATA COLLECTION SHEET - DATE

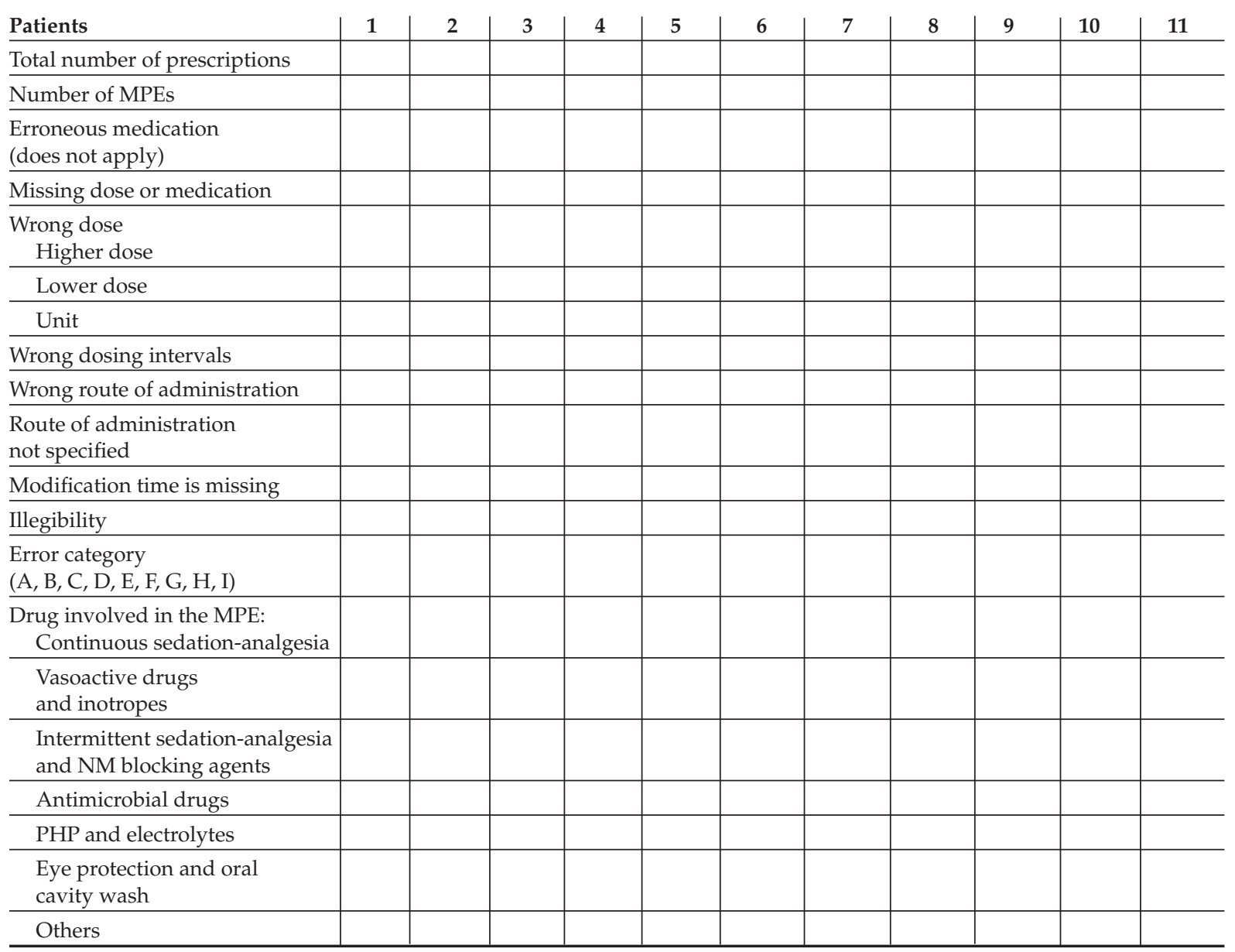

MPE: medical prescription error.

NM: neuromuscular.

PHP: parenteral hydration plan. 


\title{
Annex 2. Measures taken during the proposed intervention
}

\author{
a. Health staff education and training on patient safety. \\ Courses were provided with the purpose of: \\ - Reporting the results of the research. \\ - Creating awareness regarding the relevance and consequences of MPEs. \\ - Disseminating the content of the package of improvement measures and how to implement it.
}

Courses lasted 30 minutes and were addressed to all PICU staff members (physicians, nurses). All on-call services in the week and all nursing shifts received the same course, which was mandatory. The purpose was to submit findings of the period Diagnosis of the situation and to compare them with those published in the literature. Concepts concerning patient safety and specifically concerning errors in medication use were addressed.

The courses consisted in a PowerPoint presentation including charts and tables which summarized the results of the pre-intervention period of the research, and the development of improvement measures to be implemented.

The physicians responsible for the project were in charge of the courses and of checking attendance. Staff training concluded once all PICU staff members had attended at least one of the courses.

Posters including charts and tables with the results were prepared and distributed among the different areas (physicians' room, nurses' room, front desk at the Unit and medication preparation area).

b. Inclusion and active participation of a pharmacist at the PICU.

The pharmacist participation was not limited to monitoring the prescription process and collecting data. Including a pharmacist as a member of the PICU team enabled us to optimize the whole process of medication use in its different stages, which included dispensing, preparation and administration, though these were not evaluated in this project.

\section{c. Implementation of daily feedback on MPEs}

Daily feedback on MPEs was carried out during morning medical rounds, and was led by any of the physicians responsible for the research or by the PICU pharmacist. On such rounds, in which the different Unit providers (physicians, nurses and kinesiologists) participated, the type of error made and its possible consequences, if any, were discussed before each patient. The purpose was to raise awareness and obtain full participation of those in charge of patients' care regarding patient safety, so as to prevent or minimize future events.

d. Updated edition of available and accessible drug and treatment formularies.

New updated drug and treatment formularies were purchased and distributed among the different areas, so that they would be available to all staff members (physicians' room, nurses' room, front desk at the Unit and medication preparation area). Staff members were advised to check indications several times, and verify dosing, dosing intervals, etc. against the respective formularies of the drugs indicated.

e. Laminated charts of dilution and infusion guidelines for main drugs, and laminated charts including the main antimicrobial drugs, dosing and dilution.

Those in charge of the research and the pharmacist prepared laminated charts which were grouped in folders and exhibited in the different PICU areas.

f. Development of a computerized prescription system.

The Department of Information Systems at the HGNPE developed a program for computerized medical prescriptions. The process of adjustment and continuous improvement of such system took place during the intervention period (September and October). A pilot test of the program was performed with the participation of all physicians at the PICU, both staff and on-duty on-call physicians, in order to get feedback and implement further improvements. In addition, both the system and the printed sheet resulting from the computerized prescription were submitted to nurses for their assessment, feedback from the various providers was collected, and those modifications judged suitable and feasible were introduced. 